\title{
STD/ AIDS Asia and world perspective
}

\author{
SM Rasel Faruk ${ }^{1 *}$, MU Kabir Chowdhury ${ }^{2}$, SM Bakhtiar Kamal ${ }^{3}$, Sarker Mahbub Ahmed Shamim ${ }^{4,5}$ and Imrose Mohit ${ }^{6}$ \\ ${ }^{1}$ Senior Consultant, National Skin Centre, Dhaka, Bangladesh \\ ${ }^{2}$ Department of Dermatology, MH Shamorita Medical College Hospital, Dhaka, Bangladesh \\ ${ }^{3}$ Department of Dermatology, Dhaka Medical College Hospital, Bangladesh \\ ${ }^{4}$ Chief Consultant, department of dermatology, Laser treat, Dhaka, Bangladesh \\ ${ }^{5}$ Senior Consultant, Aesthetic Laser, Dhaka, Bangladesh \\ ${ }^{6}$ Department of dermatology, Delta Medical College Hospital, Dhaka, Bangladesh
}

\begin{abstract}
Sexually transmitted diseases (STDs) including the acquired immunodeficiency syndrome (AIDS) continue to spread alarmingly in South-East Asia and pose a major public health and developmental threat to the countries of this Region. Although HIV began to spread in Asia much later than it did in the United States and Africa, it is already having considerable impact in many countries as seen by the rapid increase in infection rates among various population groups including the general population. Given the presence of risk behaviour factors, such as high rates of STD, male patronage of sex workers, and low usage of condoms, there is an enormous potential for spread in all countries of the Region. While countries are responding to the pandemic to their best capabilities, much more remains to be achieved in terms of political commitment, appropriate societal response and in the speedy and efficient implementation of programme activities, in the areas of both prevention and care. This article provides a short summary of the current status of sexually transmitted infections (STIs)/HIV epidemiology in the Asia-Pacific region and the world. Information was requested from WHO, UNAIDS as well as from STI experts in a number of major nations in the region. Reliable national STI notification statistics were not available from several of these countries. Varying rates of notification and completeness of data make direct comparison between countries difficult. However, within country trends do provide an idea of the epidemics in the respective countries.
\end{abstract}

\section{Introduction}

The Asia and Pacific region was home to an estimated 5.2 million people living with HIV in 2017. China, India and Indonesia account for almost three-quarters of the total number of people living with HIV in the region. It is increasingly clear that the Asia and Pacific region is falling behind Africa in its HIV response. In 2017, 74\% of people living with HIV in this region were aware of their status. Among those diagnosed with HIV, $71 \%$ were on treatment and $85 \%$ were virally suppressed [1]. The epidemic is largely characterized by concentrated and growing epidemics in key populations in a variety of countries, particularly clients of sex workers and other sexual partners of key populations, and men who have sex with men (sometimes referred to as MSM). Low national prevalence masks much higher prevalence among these groups and in specific locations, particularly urban areas [2].

\section{Discussion}

The Philippines has registered the fastest-growing HIV/AIDS epidemic in the Asia-Pacific in the past six years with a 140-percent increase in the number of new infections [3]. HIV (HIV-1) epidemics in Asia show great diversity, both in severity and timing. But epidemics in Asia are far from over and several countries including China, Indonesia, and Vietnam have growing epidemics. Several factors affect the rate and magnitude of growth of HIV prevalence, but two of the most important are the size of the sex worker population and the frequency with which commercial sex occurs. Although access to antiretroviral therapy is increasing globally, making it work effectively while simultaneously expanding prevention programmes to stem the flow of new infections remains a real challenge in Asia [4]. Availability of a knowledge of status measure among people living with HIV (\%) Asia and the Pacific is 99\%,
Middle East and North Africa is 80\% [5]. About 36.9 million people globally were living with HIV in 2017. About 21.7 million people were accessing antiretroviral therapy in 2017. About 1.8 million people became newly infected with HIV in 2017. About 940000 people died from AIDS-related illnesses in 2017. About 77.3 million people have become infected with HIV since the start of the epidemic. About 35.4 million people have died from AIDS-related illnesses since the start of the epidemic [6]. About 5000 new HIV infections (adults and Children) a day in 2016. About $64 \%$ are in sub-Saharan Africa, about 4500 are among adults aged 15 years and older of whom: $43 \%$ are among women [7]. Although it is well known and accepted that FSW are a highly vulnerable group in the scope of the HIV epidemic, most countries in the world do not know the size of this population group. The estimates of the prevalence of FSW presented in this paper show how important this hard-to-reach population group is in all parts of the world [8]. Afganistan is one of the poorest in the world and experiences extremely high levels of economic migration, with attendant vulnerability to HIV transmission. They are in the early stages of drug injectionassociated epidemics of HIV infection [9]. More than 1 million sexually transmitted infections (STIs) are acquired every day worldwide. Each year, there are an estimated 357 million new infections with 1 of 4 STIs: chlamydia, gonorrhoea, syphilis and trichomoniasis. New Emerging

${ }^{\star}$ Correspondence to: SM Rasel Faruk, Senior Consultant, National Skin Centre, Dhaka, Bangladesh, Email: smrfaruk@gmail.com

Key words: STD, HIV

Received: September 10, 2018; Accepted: September 18, 2018; Published: September 21, 2018 
infection that is, Ebola and Zika viruses can be transmitted sexually [10]. HPV16 was the most common type, with a prevalence of $4.8 \%$ in general population and $6.0 \%$ in fertility clinic attendees. A significantly increased risk of infertility was found for males with HPV positivity in semen. Seminal HPV infection is common worldwide, which may contribute to the risk of male infertility [11]. About 536 million people are estimated to be living with incurable herpes simplex virus type 2 (HSV-2) infection, approximately 291 million women have a human papillomavirus (HPV) infection at any given point in time, the burden of STIs is greatest in low-income countries [12]. The majority (76\%) of people diagnosed with HIV in 2016 were men, and the highest proportion of all new diagnoses (40\%) were attributed to sex between men. Heterosexual contact accounted for $32 \%$ of cases and injecting drug use for $4 \%$ [13]. More than 30 different bacteria, viruses, and parasites lead to greater than 1 million sexually transmitted infections each day. Chlamydia (with an estimated 131 million new infections annually), gonorrhea (78 million infections), syphilis (5.6 million infections), and trichomoniasis (143 million infections) are 4 of the most common infections worldwide [14]. Vaginal infection with $\mathrm{T}$. vaginalis at mid-gestation was significantly associated with low birth weight [15]. Seropositivity to HSV-2 is higher in HIV-infected persons and adults of lower socioeconomic status. Most women (80\%) with HSV-2 antibodies have no clinical manifestations. Untreated early syphilis in pregnant women results in perinatal death in up to $40 \%$ of cases and, if acquired during the four years preceding pregnancy, leads to infection of the fetus in over $70 \%$ of cases [16]. Commercial sex has been an important factor in the spread of HIV/AIDS in Asia. A number of programs have been developed to reduce the level of infection among sex workers and clients, including peer education, group education, counseling, condom distribution, and treatment of sexually transmitted diseases (STDs) [17]. Among the 4390 HIV positive patients of Taiwan, 54.5\% of patients reported they were men having sex with men (MSM), but the actual percentage of MSM was probably much higher, because male homosexuality remained a social taboo in Taiwan. After implementing a policy of providing free access to HAART to all HIV-infected citizens, the HIV transmission rate decreased by $53 \%$ in Taiwan [18].

\section{Conclusion}

Awareness and education about sexually transmitted infections and human immune deficiency virus is very important to reduce the prevalence of STIs and AIDS. Use of condom is also a part of STD prevention. Social media can play an important role to educate people regarding AIDS and STDs. Government and non-government agency both have some social responsibility to guide people. Free access to highly active anti-retroviral therapy is a good provision to decrease HIV transmission. Human papilloma virus infection in male may contribute to male infertility. Major HIV affected groups in Asia and Pacific region; 1 . Men who have sex with men 2. People who inject drugs. 3. Transgender people in Asia and the Pacific. 4. Commercial sex workers.

\section{References}

1. UNAIDS (2018) Data Book.

2. UNAIDS (2016) Prevention Gap Report.

3. MANILA (2007) Philippines has highest HIV infection growth rate in Asia-Pacific: U.N Available at: https://www.reuters.com/article/us-health-aids-philippines/philippineshas-highest-hiv-infection-growth-rate-in-asia-pacific-u-n-idUSKBN1 AH3CW [Accessed 01 August 2007].

4. Kiat R, Brown T, Phanuphak P (2004) HIV/AIDS in Asia. The lancet 364: 69-82.

5. UNAIDS (2017) special analysis.

6. UNAIDS (2018) Global HIV \& AIDS statistics 2018 fact sheet. Available at: http:/ www.unaids.org/en/resources/fact-sheet [Accessed 05 September 2018]

7. UNAIDS (2017) Global AIDS Monitoring.

8. Vandepitte J, Lyerla R, Dallabetta G, Crabbe F, Alary M, et al. (2018) Estimates of the number of female sex workers in different regions of the world. BMJ Journal 82: 1-10.

9. Renton A (2006) Epidemics of HIV and sexually transmitted infections in Central Asia Int J Drug Policy 17: 494-503.

10. WHO (2018) Sexual and reproductive health. Available at: http://www.who.int reproductivehealth/topics/rtis/en/ [Accessed 04 September 2018]

11. Lyu Z, Feng X, Li N, Zhao W, Wei L, et al. (2017) Human papillomavirus in semen and the risk for male infertility: a systematic review and meta-analysis. BMC Infectious Diseases 17: 714. [Crossref]

12. WHO (2013) Sexually transmitted Infections.

13. ECDC (2016) HIV and AIDS. In: ECDC. Annual epidemiological report for 2016. Stockholm

14. Low N, Broutet N, Turner R (2017) A Collection on the prevention, diagnosis, and treatment of sexually transmitted infections. PLoS Med 14: 1-10. [Crossref]

15. Cotch MF, Pastorek JG, Nugent RP, Hillier SL, Gibbs RS (1997) Trichomonas vaginalis associated with low birth weight and preterm delivery. The Vaginal Infections and Prematurity Study Group. Sex Transm Dis 24: 353-60. [Crossref]

16. Carlos T, Da Ros, Caio da Silva Schmitt (2008) Global epidemiology of sexually transmitted diseases. Asian J Androl 10: 110-114. [Crossref]

17. Ford K, Wirawan DN, Reed BD, Muliawan P, Wolfe R (2002) The Bali STD/AIDS Study: Evaluation of an Intervention for Sex Workers. Sex Transm Dis 29: 50-58. [Crossref]

18. Fang CT, Hsu HM, Twu SJ, Chen MY, Chang YY (2004) Decreased HIV Transmission after a Policy of Providing Free Access to Highly Active Antiretroviral Therapy in Taiwan J Infect Dis 190: 879-885. [Crossref]

Copyright: (C2018 Faruk SMR. This is an open-access article distributed under the terms of the Creative Commons Attribution License, which permits unrestricted use, distribution, and reproduction in any medium, provided the original author and source are credited. 